

\section{Structure of Higher Education in India}

At the time of Independence of India, there were only 20 Universities and 500 Colleges in the country with 2.1 lakh students in higher education. The number has now been increased 40 times in the case of the Universities, 82 times in the case of Colleges. The students enrolment has gone up to over 127 times in the formal system of higher education in comparison to the figures at the time of independence. As on 31.03.2015, the number of Universities had gone up to $711-(46$ Central, 329 State, 205 State Private, 128 Deemed to be Universities, three Institutions established under State Legislation) and 40760 colleges in the Higher Education sector. So far as the number of universities in states is concerned, Rajasthan tops the list with 68 universities, followed by Uttar Pradesh (64), Tamil Nadu (52).

In India, "University" means an institution established or incorporated by or under a Central Act, a Provincial Act or a State Act and includes any such institution as may, in consultation with the University concerned, be recognised by the University Grants Commission
(UGC) in accordance with the regulations made in this regard under the UGC Act, 1956.

Higher Education is the shared responsibility of both the Centre and the States. The coordination and determination of standards in Universities \& Colleges is entrusted to the UGC and other statutory regulatory bodies. The Central Government provides grants to the UGC and establishes Central Universities/Institutions of National Importance in the country. The Central Government is also responsible for declaring an educational institution as "Deemed-to-be University" on the recommendations of the UGC. There are some autonomous agencies for establishing and regulating the universities and institutions. This includes any policy directive concerning the national agenda through the statutory bodies like UGC and other bodies responsible for governing the performance of the higher education institutions in terms of course content, duration of courses of study etc., particularly, with respect to matters concerning maintenance of uniformity of norms and standards of higher education.

Table: 1 Growth of Institutions at various levels

\begin{tabular}{|c|c|c|c|c|}
\hline Year & Universities & Colleges & Enrolment & Teachers \\
\hline $1950-51$ & 28 & 578 & 0.174 & 0.24 \\
\hline $1960-61$ & 45 & 1819 & 0.557 & 0.62 \\
\hline $1970-71$ & 93 & 3227 & 19.56 & 1.9 \\
\hline $1980-81$ & 123 & 4738 & 27.52 & 2.44 \\
\hline $1990-91$ & 184 & 5748 & 49.25 & 2.71 \\
\hline $2000-2001$ & 266 & 11146 & 83.99 & 3.95 \\
\hline $2010-2011$ & 523 & 33023 & 169.75 & 8.17 \\
\hline $2014-2015$ & 711 & 40760 & 265.85 & 12.61 \\
\hline
\end{tabular}

Note: Universities include central, state, private, deemed, institutions of national importance and colleges, government and private

Sources: Annual Reports of the UGC, Various years.

From 1950-51 to 2015, while the number of universities has increased from 28 to 711 , the number of colleges has gone up from 578 to 40760 . During this period, enrolment in higher education has registered a steep hike from 0.174 million to 265 Million. The number of teachers has also gone up from around 24,000 in 1950-51 to 12.61(Million) in 2014-15.

Figure1 shows that the growth of institutions of higher education in India has increased. 
International Journal of Trend in Scientific Research and Development (IJTSRD) ISSN: 2456-6470

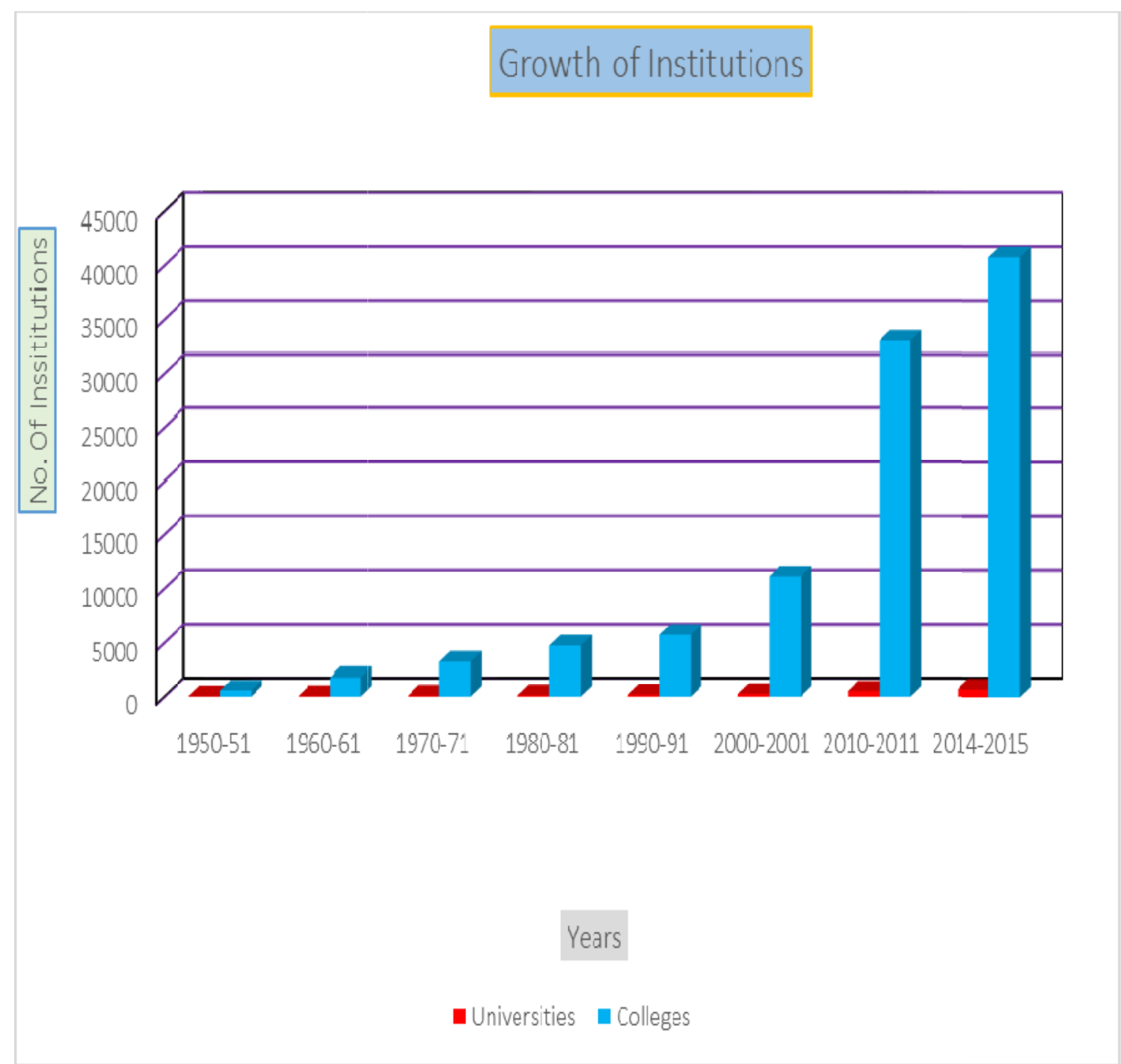

Figure 1: Growth of Institutions since Independence

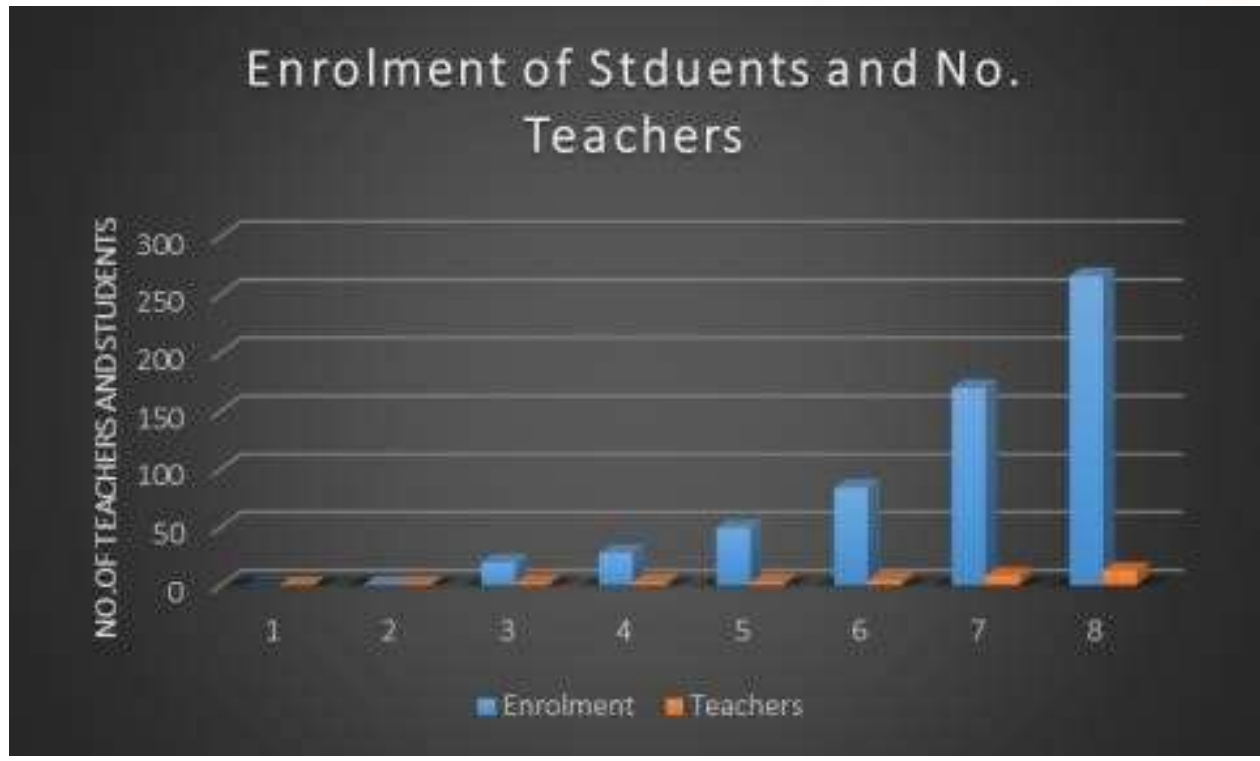

Figure 2: Enrolment of students and Number of Teachers since Independence 


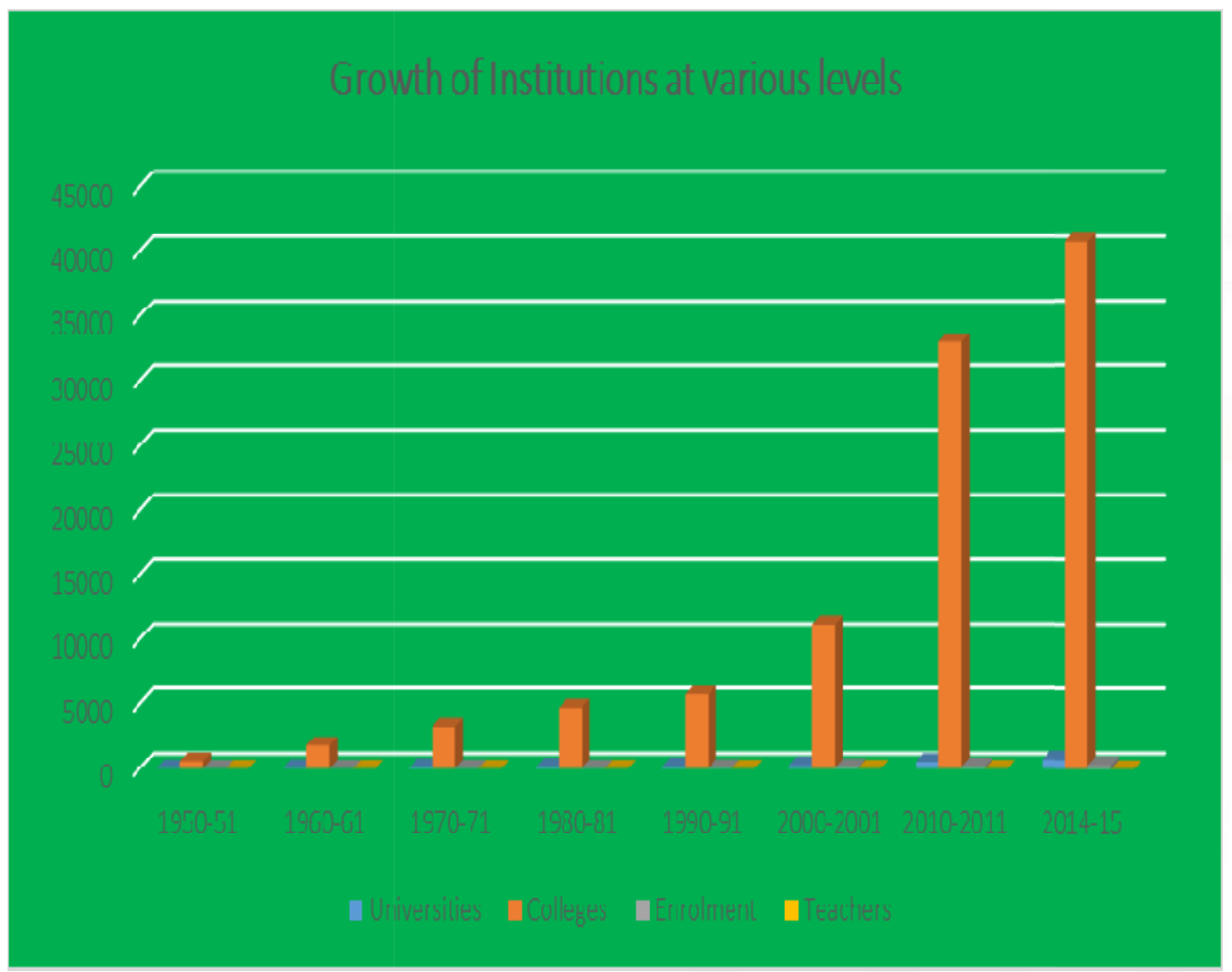

Figure 3: Growth of Institutions at various levels

\section{Attainments in Higher Education in India}

There is a network of nearly 300 specialized science and technology institutions, including more than 200 laboratories. Besides, there are 1914 polytechnics and a large number of industrial research and development laboratories in both private and public sectors. There are 15 Indian Institutes of Technology (IITs), 13 Indian Institutes of Management (IIMs), 30 National Institutes of Technology (NITs), and 24 Indian Institutes of Information Technology (IIITs). There are 3,000 colleges of engineering, technology and architecture, 2100 Medical Colleges, 3,400 Teacher Training Colleges, and nearly 3,000 other professional and technical institutions in the areas such as agriculture, law, management, computer applications and information technology.

Thus, in the case of both general and technical or professional education, a significant expansion has taken place in the post-Independence period, and higher education, on the whole, is fairly democratised. The expansion also enabled the country to be self-reliant in its manpower needs and to even 'export' manpower to other countries. With the immense increase in the institutions of higher education in India, enrolment of the students has increased. It is already mentioned above that Indian higher education system is the largest systems in the world in terms of enrolment. In recent time, total enrolment in higher education is about 33.3 million, in which 17.9 million boys and 15.4 million girls participate. There is increase of Gross Enrolment Ratio in higher education in India. At present, GER is 26.6 of 18-23 years age group. As far as the number of teachers is concerned, it has also increased. Governments have also taken many steps to increase the quality of higher education. Many incentive schemes are being introduced and implemented by the UGC such as, University Grants Commission provides JRF to the candidates who qualify National Eligibility Testing (NET/JRF) of the UGC and the UGC-CSIR. The total tenure of fellowship is for five years. These fellowships help students financially and it encourages students to do best in research. There are lot of other fellowships and scholarships in higher education to achieve the goal of higher education. Rajiv Gandhi National Fellowship for Students with Disabilities, SCs and STs, Maulana Azad National Fellowships for Minority Students, National Fellowship for Students of Other Backward Classes (OBC), Post-Graduate Scholarships for SC/ST Students in Professional Courses, swaranjayanti Award in technical education, 
are the fellowships to achieve the goal of enrolment and best research in higher education.

At present, scenario of higher education is now expanding like never before in terms of number of students, teachers, Institutions, infrastructure, monitoring, financing, management quality are the new issues. Due to this rapid increase in Higher education, the system is now becoming more and more complex and rigid. It raised many challenges and problems in higher education which may be important for the improvement of system.

\section{Challenges in Higher Education}

\section{Access}

India's GER is lingering around 19 percent at the moment, 6 percent below the world average and at least 50 percent lesser than countries such as Australia and the United States of America. GER stands for Gross Enrolment Ratio, or the percentage of students enrolling into higher education institutes each year post high school. Therefore, this is big challenge to attain 30 percent enrolment to us. The total enrolment under all faculties is over 26 million (265 lakhs).

\section{Low quality, money making Institutes.}

As a result of that huge gap, people who have no reason to be in the field of education want to capitalize on the shortage of supply. It's no secret that the education industry has long lost its noble cause and is more of a business. Politicians, realtors, businessmen/women basically anybody who wants to mint some serious cash, start to open colleges.

\section{Ineffective Foreign investment in Higher Education in India}

In September of 2013, the Government of India passed an executive order to allow the top 400 universities in the world to set up campuses in India and allow them to function independently, without the requirement of Local Partners. This sounded promising and one can see the possibilities when universities such as Duke University and Georgia Tech, both among the top fifty U.S Universities, started to show interest. A major concern of opening gates to foreign investors was that it would ruin traditional and local industries, while also forcing the shutdown of many small scale industries. If that means death to all the low-quality-cash generation types of colleges, it can only be good news. Another trade in, more importantly, is students here get access to qualified and world class educators.

\section{Equity:}

It is important that the increased access to higher education should be inclusive. The representation of SCs, STs, OBCs, PWD, Minority and other minority communities in higher education is less than their proportion in the population. Education, particularly higher education, is being looked at providing avenues for social mobility for the marginalised sections. Indeed, the recent spurt in the demand for reservations for Other Backward Classes (OBCs) may be a reflection of the important role of higher education in social mobility. We can no longer afford to ignore such demands. Neither these demands can be satisfied with tokenism. Plans are afoot to nearly double the intake capacity of the central institutions to accommodate the demand emerging out of reservations. At the same time, we should also guard against the dilution of standards. Extending access through substandard institutions will be of no good as it will segment the higher education and help in reproducing the socio-economic inequalities. High academic standards should be maintained with due consideration to special needs of marginalised groups. Students from marginalised groups should be helped through special arrangements for the required academic rigour. It has also been noticed that the students from the marginalised sections tend to concentrate in certain easy disciplines. They should be encouraged to take more progressive and hard disciplines so that social equity in higher education assumes utmost importance.

\section{Research and Development:}

Research and higher education are complementary to each other. Moreover, India's higher education institutions are poorly connected to research centres. So this is the area of challenge to the higher education in India.

\section{Faculty Shortage:}

According to a recent report of HRD Ministry premier educational institutes like the Indian Institute of Technology (IITs) and the Indian Institute of Management (IIMs) are facing a faculty crunch with nearly one-third of the posts vacant. According to a report published in IANS around 35 percent posts are vacant in the central universities, 25 percent in the IIMs, 33.33 percent in the National Institute of Technology (NITs) and 35.1 percent in other central education institutions coming up under the Human Resource Development (HRD) Ministry. However in 
order to overcome this, government is planning to have short-term measures like raising the retirement age in teaching posts from 62 to 65 years and enhancement in salaries and other benefits for teachers. Also some long-term measures have also been initiated for attracting young people to opt for this (teaching) career. These include enhancement in fellowships and attractive start-up grants in various disciplines.

\section{Privatisation:}

The higher and technical education in India is being increasingly privatised in multiple ways. On the one hand, the public institutions had to resort to cost recovery methods to stem out from financial crisis. On the other, private institutions are cropping in large numbers changing the very face of higher and technical education. In the context of the limited capacity of the public institutions and the existence of differentiated demand, we need to ensure how the two can co-exist. It is, therefore, imperative to strengthen the regulatory mechanism so that the divisive nature of private education can be contained.

\section{Internationalisation of higher education:}

Another challenge faced by the higher education is its internationalisation, not in the traditional sense of sharing experiences, but by way of international trade in educational services. Indeed, several foreign institutions have already been operating in India. Many of these institutions have been resisting any form of regulation. Some institutions of Indian origin and also a few public institutions are showing keen interest in going abroad to establish off-shore campuses. In fact, some of them have already set up their offshore campuses.

\section{Lack of relevant opportunities}

It is very clear that higher education given by various institutions, are not providing that kind of education which is suitable to get sustainable opportunity of job in private sector as well as government. Minimum numbers of institutions are able to place students in both sectors.

\section{Cost of Education}

One of the main factors of lower enrolment in technical education is the cost of education. Technical education sometimes is only a dream for most of the students of middle class families where the people are mostly dependent on agriculture and other allied sector. So it is also a challenge for the government and policy makers to overcome the high cost of education.

\section{Autonomous status of University and other Institutions}

It is evident that the institutions of higher education can achieve the goal of their existence, vision, mission, advancement and sustained development, but it can possible when adequate freedom will be given to them. There is a need for adequate freedom to define academic goals and objectives. Political and bureaucratic interferences are a big challenge to the institutions.

\section{Inadequate physical infrastructure}

Quality education is possible when facilities, resources and technologies are upgraded. For this funding is needed which has been made on the basis of grades given by NAAC on the basis of various parameters. Some higher educational institution are found in the lower side since quality of input is also very low, higher ratio of teacher-students, poor communication etc. and due to this grants are also given on the lower side which hinders improvement in physical infrastructure.

\section{Summary and Conclusion}

This paper presented the present scenario of higher education in India by analysing the various data and also identifies the key challenges like, quality education, access and equity, research and development and faculty shortage in India's higher education sector. In this paper also identified the key initiatives from the government side which include the independent regulatory authority for accreditation and national database of academic qualification, increase in number of universities including IITs, IIMs and NITs. Looking at the present scenario of the higher education in India we recommended some points in order to further meet the challenges. The journey of higher education in India along the Post-Independence era has witnessed some creditable achievements in the field of higher education resulting into overall growth in the status of higher education in India but at the same time has resulted into bigger problems and issues in the field. Undoubtedly, manifold increase in the number of institutions of higher education both in the universities and colleges has accessed yet the accessibility to higher 
education in the country has not achieved the desired standards.

\section{REFERENCES:}

1. AISHE (2013-14). All India Survey on Higher Education. Government of India, Ministry of Human Resource Development, Department of Higher Education, New Delhi.

2. AISHE (2014-15). All India Survey on Higher Education. Government of India, Ministry of Human Resource Development, Department of Higher Education, New Delhi.

3. Khanna, S.K (2009). Higher, Technical and Professional Education in K.Sudha Rao, Educational Policies in India: Analysis and Review of Promise and Performance. The Publication Unit, NIEPA.

4. MHRD (various years). Annual Reports on Higher Education.
5. Patel, I. G. (1991). Higher Education and Economic Development, in JBG Tilak, Education Society and Development: National and International Perspectives. APH Publishing Corporation for NIEPA.

6. Premi, Kusum. K (2009). Access, Equity and equality in Education with Focus on SCs, STs and Girls in K. Sudha Rao, Educational Policies in India: Analysis and Review of Promise and Performance. The Publication Unit, NIEPA.

7. Singh, D.P (2015). Autonomy for Good Governance in Higher Education: Issues and Strategies. University News, A weekly Journal of Higher Education.

8. University and Higher Education, http://mhrd.gov.in/university-and-higher-education

9. University Grants commission (UGC) (Various years): Annual Reports, 2004 onwards, UGC, New Delhi. 